\title{
Erratum zu: Best-Practices für die Gestaltung von IT-Service-Katalogen und den Einsatz von Self-Service-Portalen
}

\author{
Sebastian Floerecke (iD
}

Angenommen: 20. Mai 2021 / Online publiziert: 25. Juni 2021

(C) Der/die Autor(en) 2021

\section{Erratum zu:}

\section{HMD 2020}

https://doi.org/10.1365/s40702-020-00702-y

Der Artikel Best-Practices für die Gestaltung von IT-Service-Katalogen und den Einsatz von Self-Service-Portalen von Sebastian Floerecke wurde ursprünglich am 23. Dezember 2020 ohne „Open Access“ online auf der Internetplattform des Verlags publiziert. Die Autoren haben sich jedoch nachträglich für eine „Open Access“-Veröffentlichung entschieden. Das Urheberrecht des Artikels wurde deshalb am 11. Mai 2021 in ( Der/Die Autor(en) 2020 geändert.

Funding Open Access funding enabled and organized by Projekt DEAL.

Open Access Dieser Artikel wird unter der Creative Commons Namensnennung 4.0 International Lizenz veröffentlicht, welche die Nutzung, Vervielfältigung, Bearbeitung, Verbreitung und Wiedergabe in jeglichem Medium und Format erlaubt, sofern Sie den/die ursprünglichen Autor(en) und die Quelle ordnungsgemäß nennen, einen Link zur Creative Commons Lizenz beifügen und angeben, ob Änderungen vorgenommen wurden.

Die in diesem Artikel enthaltenen Bilder und sonstiges Drittmaterial unterliegen ebenfalls der genannten Creative Commons Lizenz, sofern sich aus der Abbildungslegende nichts anderes ergibt. Sofern das betreffende Material nicht unter der genannten Creative Commons Lizenz steht und die betreffende Handlung nicht nach gesetzlichen Vorschriften erlaubt ist, ist für die oben aufgeführten Weiterverwendungen des Materials die Einwilligung des jeweiligen Rechteinhabers einzuholen.

Die Online-Version des Originalartikels ist unter https://doi.org/10.1365/s40702-020-00702-y zu finden.

Sebastian Floerecke $(\bowtie)$

Lehrstuhl für Wirtschaftsinformatik mit Schwerpunkt Informations- und IT-Service-Management, Universität Passau, Innstraße 43, 94032 Passau, Deutschland

E-Mail: sebastian.floerecke@uni-passau.de 
Weitere Details zur Lizenz entnehmen Sie bitte der Lizenzinformation auf http://creativecommons.org/ licenses/by/4.0/deed.de. 